\title{
A Caring Leadership Model for Nursing's Future
}

By: Randy L. Williams, Judy B. McDowell, Donald D. Kautz

Williams, R. L., II, McDowell, J. B., and Kautz, D. D. (2011). A caring leadership model for nursing's future. International Journal for Human Caring, 15(1), 31-35.

Made available courtesy of International Association for Human Caring, Inc.:

https://iafhc.wildapricot.org/page-18066

***(C) International Association for Human Caring, Inc. Reprinted with permission. No further reproduction is authorized without written permission from International Association for Human Caring, Inc.***

Keywords: Nursing | Leadership | Watson's Theory of Caring | Caring theory | Caring Leadership Model

***Note: Full text of article below 


\title{
A Caring Leadership Model for Nursing's Future
}

\author{
Randy L. Williams, II, RN, MSN, MBA \\ Wake Forest University Baptist Medical Center \\ Watson Caring Science Institute
}

Judy B. McDowell, RN, MSN, CCRN

Wake Forest University Baptist Medical Center

Donald D. Kautz, RN, PhD, CNE
University of North Carolina at Greensboro

\begin{abstract}
This article describes the McDowell-Williams Caring Leadership Model that brings together the caring theory of Watson (2008) and the leadership theory of Kouzes and Posner (2007). This model provides institutional guidance for continuing the effective shared governance by the nurses at Wake Forest University Baptist Medical Center (WFUBMC), as well as strategies for leaders to use with staff as they make their workplace the best place to work and the best place to receive care.
\end{abstract}

Key Words: Caring theory, Watson's caring theory, leadership theory, Caring

Leadership Model

\section{Introduction}

Hinshaw (2008) argued that the nursing profession is attempting to navigate the perfect storm as nurses strive "to build cultures of safety for patients and families while simultaneously handling an epic crisis in workforce issues" (p. S4), including a shortage of nurses, nursing faculty, and nurse leaders. Nurses have become technically and scientifically competent and specialized in our individual fields, but many of us have lost a sense of meaning in our work. Our days are busy with high tech equipment and an enormous list of tasks that must be completed. Our work is often cost restricted and quality challenged.

We use the term caring like a buzzword - the soft-stuff that we would do if we had the time. But we seem to spend a lot more time in caring for our computers, monitors, intravenous pumps, etc., than we do in caring for patients and families. Too many nurses are mentally and physically exhausted and have difficulty caring for themselves and for each other, let alone their patients. The nursing shortage has left a shortage of nurse managers, who are not grooming staff nurses to take on the leadership role when manager turnover occurs (Wendler, Olson-Sitki, \& Prater, 2009). We believe teaching and role modeling the principles of caring, blended with the principles of leadership, can change the culture of an organization.

Wake Forest University Baptist Medical Center (WFUBMC) is a large academic medical center with 872 licensed beds in the southeastern United States. It was the first Magnet-designated hospital in the Carolinas. Lexington Memorial is a community-based WFUBMC hospital with 94 licensed acute care beds.

We believe that the core of the workforce issue is a loss of trust and confidence in both leaders and our organizations.

Recognizing the problem, nurses have implemented the McDowell-Williams Caring Leadership Model at WFUBMC. Two of the authors, (McDowell and Williams) developed and implemented the Caring tion with their work with the Watson Caring Leadership Model at WFUBMC in conjunc-
Science Institute. The leadership model has been implemented in both hospitals with nurse leaders from over 50 patient care areas. The leaders represent diversity in ethnic backgrounds, age, gender, education, and years of experience. The McDowellWilliams Caring Leadership Model brings together the caring theory of Watson (2008) and the leadership theory of Kouzes and Posner (2007).

Watson's (2008) theory of human caring focuses on preserving humanity and human dignity and gives the practitioner a solid foundation upon which to carry out their work. Her theory may seem complex and difficult to understand, but once the light comes on, the depth of understanding grows exponentially. The theory grows inside each one of us and our practice changes direction, shedding light all around us. Watson's (2008) work was organized around 10 carative factors that provided a format and focus for nursing. Over the last few decades, her theory has evolved into a philosophy with 10 enhanced Caritas Processes that address the essence of caring. The word caritas comes from the Latin word meaning to cherish, to appreciate, and to give special attention. Caritas shows maturity and an integration of our past with our present and future, moving our work to transforming self and those we serve, including our institutions and our profession itself. Table 1 includes the brief descriptions that we have provided staff at WFUBMC to assist them to implement the 10 Caritas Processes in 
Table 1

WFUBMC's Conceptualization of Watson's 10 Caritas Processes

1. Practice of loving-kindness and equanimity within the context of caring consciousness. Take a breath and ask, "Why am I here?" Pause in chaos, go back to your core values and repattern yourself.

2. Being authentically present and sustaining the deep belief system and subjective life world of self and one-being-cared for. Be present in the moment. Be mindful of what you are doing and do it with the intention to care. Your very presence may be the difference between hope and despair.

3. Cultivation of one's own spiritual practices and transpersonal self, going beyond the ego self. Become more self-aware. Honor and offer loving-kindness to self; even those aspects we fear or dislike. Commitment to caring-healing requires focusing on our personal/professional growth.

4. Developing and sustaining a helping-trusting, authentic caring relationship. Building caring relationships requires deepening our humanity; being compassionate, aware, and awake to others' dilemmas.

5. Being present to and supportive of the expression of positive and negative feelings as a connection with deeper spirit of self and the one-being cared for. Choose how to be in relationships and encounters with others. We have a responsibility to transform patterns of toxicity in our organization.

6. Creative use of self and all ways of knowing as part of the caring process, to engage in the artistry of caring-healing practices. Caring involves all ways of knowing, including understanding, insight, reflection, and wisdom.

7. Engage in genuine teaching-learning experiences that attend to unity of being and meaning attempting to stay within other's frame of reference. Learning involves a meaningful and trusting relationship, honoring the whole person.

8. Creating healing environment at all levels, physical as well as non-physical, subtle environment of energy and consciousness, whereby wholeness, beauty, comfort, dignity, and peace are potentiated.

9. Assisting with basic needs, with an intentional caring consciousness, administering "human care essentials," which potentiate alignment of mind-body-spirit, wholeness, and unity of being in all aspects of care. When touching another body, we are also touching the mind, the heart, and the soul. Meeting the basic needs of the body is a sacred act.

10. Opening and attending to spiritual, mysterious, and existential dimensions of one's own life and death; soul care for self and one-being-cared for. Be open to mysteries. Recognize we do not have all the answers. Allow for miracles.

their daily practice.

A core principle of Watson's (2008) theory is that nurses have a moral commitment to form transpersonal relationships with others. Nurses "seek to recognize, honor, and accurately detect the spirit of the other through genuine presencing, being centered, available in the now-moment" (Watson, 2008, p. 81). Healing and caring occur in caring moments shared between two people when the nurse connects at a spirit-to-spirit level with another. It is in that moment that both lives are forever altered.

The practical application of this theory is our institution's model of care. This is a model of care based on three primary tenets: care of the patient/family, care of the team, and care of the self. Implementation of the model entails unit development of behavioral expectations that embody what the model looks like on the particular unit. The foundation for the implementation of our model is a robust shared governance structure, which empowers every direct care nurse to have a voice in decisions that affect their practice and the expectations of how that practice will be carried out.

Our hospital's shared governance
(McDowell et al., 2010) is the vehicle for implementing a model of care that focuses on the essence of nursing: caring. Within the shared governance structure every nurse in the organization belongs to a unit-based council. These councils establish expectations for how the three tenets of our institution's caring relationship-based model will be actualized in a way that is appropriate for the population being cared for.

Shared governance leaders have extraordinary responsibility, authority, and accountability and, therefore, must have education and experience with leadership

\section{International Journal for Human Caring}


skills and must be mentored to develop and enhance those skills. The leadership theory of Kouzes and Posner (2007) is being used to guide this process. This theory evolved from a survey, The Leadership Practices Inventory, which was given to over 75,000 people over a 20 -year period. The data acquired led to a list of common characteristics of leaders functioning at their personal best. From this base, Kouzes and Posner (2007) developed the "Five Practices of Exemplary Leadership." Their work is based on the belief that leadership is, above all, a relationship that is values based with a foundation of credibility. They emphasized that credibility and trust are the connectors of the utmost importance in stabilizing relationships. Their concept of leadership is also intentional: leading is a choice.

Mastery of leadership requires mastery of the skills central to developing and maintaining positive relationships with others. A brief description of how we have implemented Kouzes and Posner's (2007) five practices at WFUBMC is presented in Table 2. Leaders must be taught the skills that will enable them to listen, to communicate, to resolve conflicts, to negotiate, to influence, to build teams, and to strengthen the capacity of others to excel.

Leadership matters and it matters more in times of uncertainty than in times of stability. Since leadership matters more in times of uncertainty, then leadership development matters more now than ever.

We have integrated Watson's (2008) caring theory and Kouzes and Posner's (2007) leadership theory by integrating the Five Practices of Exemplary Leadership with the 10 Caritas Processes as is illustrated in Table 3. These theories complement each other and can provide an effective basis for leadership.

Blending these theories led to the McDowell-Williams Caring Leadership Model, which suggest that leaders must adopt the following core values:

- Always lead with kindness, compassion, and equality.

- Generate hope and faith through cocreation.

- Actively innovate with insight, reflection, and wisdom.

- Purposely create protected space founded upon mutual respect and caring.

- Embody an environment of caringhelping-trusting for self and others.

Each of these core values is illustrated by comments from nurse leaders in our organization:

- Always lead with kindness, compas- sion, and equality.

I have two registered nurses in my department who desire to cut back on their work hours. These employees are long-time, seasoned nurses. I sat down with both of these employees and allowed them to discuss their concerns and wishes. We are in a trial period with their schedules.

- Generate hope and faith through cocreation.

I am getting ready to complete my masters and my endurance and survival in the program is due to a col league who is able to see my gifts and is willing to help me stay focused so I can accomplish my goals.

- Actively innovate with insight, reflection, and wisdom.

When I was a new employee, my mother died the very week I started. When I flew home, I found a card and flowers from my boss. The card showed she understood what I was going through, but also that she valued me as a new member of our team.

- Purposely create protected space founded upon mutual respect and car ing.

Our staff has young families and may need to take time off. They do not want

Table 2

Implementation of Kouzes and Posner's Five Practices at WFUBMC

1. Model the way. Nurse leaders at WFUBMC share their positive experiences and discuss ideas of how to make them occur more frequently. They also identify barriers and brainstorm for strategies to help with those opportunities.

2. Inspire a shared vision. We explore together what it means to be a caring leader in our eyes and our peers. We also explore the impact that our core values have on our day-to-day leadership.

3. Challenge the process. There is an increased emphasis on decisions and their impact on a caring-healing environment for all. We acknowledge that caring as a leader is necessary if a culture of caring is desired in the organization.

4. Enable others to act. The model has wide appeal among the leaders to assist in developing a caring consciousness and leadership skills to bridge the gap between the old way of management to a purposeful acknowledgement of the importance of caring at all levels and in all actions.

5. Encourage the heart. Leaders at multiple levels appreciate the purposeful exploration of what it means to be a caring leader and the time taken to make this way of being not just an expectation, but an imperative. 
Table 3

AGAPE Caritas Leadership of Selfless Love Model

Caring Leadership Model $\mathbb{C}$

Model of Care

Patient/Family, Team, Self

\begin{tabular}{|c|c|c|}
\hline \multicolumn{3}{|c|}{ Core Values of Caring Leadership Model Crosswalk } \\
\hline Caring Leadership Model & Theory of human caring & Leadership theory \\
\hline $\begin{array}{l}\text { Always live with kindness, compassion, } \\
\text { and equality }\end{array}$ & $\begin{array}{l}\text { Practice of loving-kindness and } \\
\text { equanimity; caring consciousness }\end{array}$ & Model the way \\
\hline Generate hope and faith through co- & Being authentically present in the moment & Inspire a shared vision \\
\hline creation & $\begin{array}{l}\text { Engaging in genuine teaching-learning } \\
\text { experience }\end{array}$ & \\
\hline & $\begin{array}{l}\text { Creative use of self and all ways of } \\
\text { knowing }\end{array}$ & \\
\hline $\begin{array}{l}\text { Purposely create protected space founded } \\
\text { upon mutual respect and caring }\end{array}$ & $\begin{array}{l}\text { Creating healing environments at all } \\
\text { levels }\end{array}$ & Enable others to act \\
\hline & $\begin{array}{l}\text { Assisting with basic needs, with an } \\
\text { intentional caring consciousness }\end{array}$ & \\
\hline $\begin{array}{l}\text { Embody an environment of caring- } \\
\text { helping-trusting for self and others }\end{array}$ & $\begin{array}{l}\text { Developing and sustaining a helping- } \\
\text { trusting authentic caring relationship }\end{array}$ & Encourage the heart \\
\hline
\end{tabular}

to leave their work for someone else to do. We know what we have to do. We work as one.

- Embody an environment of caringhelping-trusting for self and others I have had a mentor take an interest in my personal growth by taking the extra time to assist my growth by both acknowledging my positive contribu tions and also caring enough to help me recognize when my actions were perceived as uncaring.

Caring is our core business in healthcare. One hears that nurses today are burned up and burned out and are having difficulty finding a reason to keep on trying. We must create cultures in hospitals that are worthy of the commitment of every person who comes to work and worthy of the trust of everyone who comes to be served. We need to serve both those who give care and those who receive care. Leaders need to find op- portunities to be present with staff. They need to try to make their workplace the best place to work and the best place to receive care.

The nursing leaders of today and tomorrow need to be nurtured in their caring consciousness and their leadership skills. A model for caring leadership can provide a foundation for establishing the caring culture that is critical for our future and for providing the leadership necessary to face 
the uncertainty and changes ahead. This is the only way to improve healthcare outcomes for the patients, staff, and for ourselves. By implementing the Caring Leadership Model we can develop courageous leaders for the future. "We will need that for a future where patient care will thrive with outstanding nursing leadership" (Cardin \& McNeese-Smith, 2005, p. 161).

Lauer (2008) believed leadership is not an affair of the head, but an affair of the heart. The best-kept secret of successful leaders is love: staying in love with leading, with the people who do the work, with the products of their organizations, and with those who honor the organization by using its products and services. Henri Nouwen (1974), the internationally renowned priest, author, and respected Harvard University professor wrrote:

Every human being has a great, yet often unknown, gift to care, to be compassionate, to become present to the other, to listen, to hear and receive. If that gift would be set free and made available, miracles could take place.

(Wesorick, 2004, p. 275)

Caring leadership could produce those miracles.

\section{References}

Cardin, S., \& McNeese-Smith, D. (2005). A

model for bridging the gap. Nursing

Administration Quarterly, 29, 154-161.

Hinshaw, A.S. (2008). Navigating the per- fect storm: Balancing a culture of safety with workforce challenges. Nursing Research, 57(1S), S4-S10.

Kouzes, J.M., \& Posner, B.Z. (2007). The leadership challenge (4th ed.). San Francisco, CA: Jossey Bass.

Lauer, C., \& the Editors at Soundview Executive Book Summaries (2008). The management gurus: Lessons from the best management books of all times. New York, NY: Portfolio Hardcover.

McDowell, J.B., Williams, II, R.L., Kautz, D.D., Madden, P., Heilig, A., \& Thompson, A. (2010). Shared governance 10 years later. Nursing Management, 41(7), 32-37.

Nouwen, H. (1974). Out of solitude. Notre Dame, IN: Ave Maria Press.

Watson, J. (2008). Nursing: The philosophy and science of caring (rev ed.). Boulder, CO: University Press of Colorado.

Wendler, M.C., Olson-Sitki, K., \& Prater, M. (2009). Succession planning for RNs: Implementing a nurse management internship. Journal of Nursing Administration, 39, 326-333.

Wesorick, B. (2004). A leadership story about caring. Nursing Administration Quarterly, 28, 271-275. 